\title{
125 JAAR NA RUSTENBURG 11 FEBRUARIE 1859
}

Prof. B. Spoelstra

\section{ONS KYK TERUG}

\section{Waaroor dit gaan}

Die feit dat gepraat word van die GKSA wat 125 jaar gelede op Rustenburg gestig is, toon hoe die kerkbegrip gekollegialiseer het. Dit was nie die motief in 1859 nie. Tereg het kollega J. H. van Wyk dan ook op die GTV-byeenkoms te Pretoria gevra: Was daar dan nie 'n kerk voor 1859 nie? Slaan "gereformeerd" nie op die Reformasie van meer as 4 eeue gelede en "kerk" op Pinkster nie? Ons kan byvoeg: Preek die dominees dan nie oor Heid. Kat. Son. 21 dat ons GLO dat die Seun van God vir Hom 'n kerk deur sy Gees en Woord in die eenheid van ware geloof van die begin van die wêreld af tot die einde toe vergader, beskerm en onderhou nie? Hoe staan dit met die kerk van Christus en wat ons die GKSA of ONS kerk noem?

In die era van rasionalisme en sekularisme het die kerkvraag wat met kerkstrukture reken, dominerend na vore getree. Sedert die Rasionalisme o.a. by monde van Rousseau in die $18 \mathrm{e}$ eeu het die idee van samelewingsverbande gegrond op sosiale kontrakte na vore gekom. Die "kerk" is ook as genootskap voorgestel wat op basis van sy eie kerkorde konstitueer.

By Rustenburg in 1859 word egter geen kerkvraag voorop gestel nie. Indien dit die geval was, sou seker die "Chr. Geref. Kerk" van Postma gestig moes gewees het. Dit gaan egter in 1859 nie oor 'n kerk as genootskap nie. Alles wentel in 1859 om die bedieningsvraag, oor wat in die plaaslike gemeentes aan die orde is. Die mense het hulle nie van 'n NHK of NGK-struktuur afgeskei om 'n derde genootskap te stig nie. Hulle het slegs 'n eie gemeente (kerk) gevorm waarin hulle op die grondslae van die Reformasie, soos omskryf deur die Sinode van Dordrecht $1618 / 19$, bedien en regeer wou word. Alle aandag trek saam op die plaaslik kerkwees en daar is geen sprake van 'n superstruktuur GKSA agter die gemeente wat die gemeente wil verteenwoordig nie.

Dit was 125 jaar gelede anders

Die kerk van 1859 was eenvoudige, ongeleerde mense, geisoleerd op plase, geïsoleerd in nog ongeordende Boere Republieke binne 'n ekonomiese woestyn. Die mense van die Kaapkolonie moes tot ongeveer 1830 van die Oranjerivier na Graaff Reinet vir kerkgeleenthede gaan. Die gevolg van die isolasie was dat nie die kerkvraag nie, maar die geloofsvraag en godsdiensvraag hulle lewens van dag tot dag beheers het. Die mense het daagliks in verhouding met God omgegaan met sy Woord. Bywoning van eredienste het feitlik net om die kwartaallikse en soms jaarlikse nagmaal gewentel. Kerk was slegs die gemeente waar genademiddele bedien word. Hulle werklike kerk was eerder die huisgemeente in familie-verband waar die vader elke Sondag in die godsdiens voorgegaan het. 
Die Sinode van 1824 het vir die eerste keer sentralisasie in die kerkregering na vore gebring. Vanaf ongeveer 1830 word meer gemeentes onder die Noordoostelike Grensboere gestig. Die mense ontmoet ineens ander dinge en ander gedagtes as waaraan hulle gewoond was. Hulle noem dit "nuwighede": Gesange, bidure, revivalpreke, rasionalisme en twyfel oor die Kategismus, "verligting", "modernisme" ens. Hulle vra krities: Is dit nodig om te verander? Wie verlang die veranderinge, die Here of mense? In hulle familieverband het ouers en kinders met die nuwe gees van die 19de eeu geworstel. Hulle aandag het saamgetrek op wat hulle in en om die eredienste, katkisasie en kerkregering ervaar het.

\section{Botsing was 125 jaar gelede onvermydelik}

Die gees van die Griekse klassieke lewensbeskouing kom uit die Renaissance en Rasionalisme die gereformeerde lewe van Europa en ook Suid-Afrika binne. Dit lê nadruk op die outonome mens wat met sy rede wat die natuur hom gee sy eie god en meester is. So kom in kerk en godsdiens die mensvraag na vore: waarvan hou die mens? Wat is sy ervaring? Wat dink hy van God, die Skrif, die godsdiens? Waar die Psalms die soewereiniteit van God voorop geplaas het, wil die mense nou liedere waarin die "moderne" lewensgevoel van die mens oor homself uiting vind.

Die behoefte aan en weerstand teen verandering word beheers deur 'n gesagkwessie. Die Roomse priesters het op grond van hulle amp aanspraak gemaak dat hulle Christus verteenwoordig. Daarom het hulle gehoorsaamheid opgeëis en heerskappy gevoer. Die Reformasie het daarteenoor die gesag van die Skrif as Gods Woord, soos ons nog in art. 7 NGB bely, opgewerp. God is alleen soewerein.

Die nuwe gees het egter by monde van die digter Kloos gesê: "Ik ben een god in het diepst van mijn gedachte". Die Liberalisme word geken aan sy verwerping van alle gesag buite die rede van die individu. Gevolglik beweer die Liberalisme dat die meerderheid van vrye individue altyd die hoogste gesag in 'n menslike samelewingsverband verteenwoordig. In die sake van geloof, godsdiens en kerk word dan ook gevra: wat wil die meerderheid in die kerk of sinode? Wat wil die mense hê?

Die Liberalisme het onverdraagsaam vyandig gebots met diegene wat aan die solas van die Hervorming wou vashou: genade alleen, Skrif alleen, geloof alleen.

\section{Gesange in die stoeikryt}

Mense wat in hulle kerkwees genoeg aan die Skrif gehad het, het die nuwe gees die eerste in die eredienste in die Evangeliese Gesange ontmoet. Uiteraard het almal in 'n kerk, groot en klein, te make met wat gesing word. Die nuwe liedere het vir hulle vreemd op die oor geval. Hulle het gevra: Is dit volgens Gods Woord? By die Afrikaanse bewerkings van die Gesange het die NG en NH Kerke verklaar dat verskillende Gesange vanweë afwykende "leerstellinge" gronde weggelaat moes word. 
In Die Kerkblad (8.2.84) het ek 'n paar dokumente uit die periode voor 1859 aangehaal. Daaruit blyk dat die krisis in Transvaal sedert die koms van die eerste predikant saamtrek op twee vrae: eerstens is die Gesange volgens Woord en tweedens moet mense wat daarteen beswaar het, verplig word om die Gesange te aanvaar? Toe die predikant in 1855 met die "Stem van Mooirivier" toegee dat hy nie met 'n beroep op die Skrif die mense kan oortuig nie, het P. A. Venter (1855) en oudl. P. H. Snyman (1856) in skrywes gevra of dit ware kerkregering is wanneer mense wat slegs by God se heilige Woord wil bly, vervolg en beledig word. 'n Groot groep mense het in 1856 onder leiding van Snyman vir die "kerkraad en leraar" van Rustenburg bedank. Let wel: hulle bedank 'n bepaalde bedieningsopset en nie 'n dié of dié kerk nie.

Ek het in my proefskrif (Die Doppers in SA 1760-1899) aangetoon dat in 1856 ook reeds 'n dolerende gemeente in Colesberg bestaan het. J. J. Venter het ook in 1856 vir die predikant en gemeente van Bloemfontein bedank. Die feite gee grond om te beweer dat die vraag na die aard van bediening en kerkregering in 1856 voorop gestaan het en dat daar hoegenaamd nie beoog was om 'n derde Afrikaanse kerkstruktuur teenoor die NHK of NGK daar te stel nie.

Die Ring van Graaff Reinet wou in 1841 die sing van Gesange verplig. Met ' $n$ Herderlike Omsendbrief het die Ring die beswaardes "skeurmakers en deurboorders van die liggaam van Christus" genoem en hulle verwyt dat hulle beter as die predikante wil weet en hulle nie deur predikante wil laat voorsê nie. In die lig van die nagmaalformulier het die beswaardes hulle van die nagmaal onthou omdat hulle tot "skeurmakers" verklaar is. J. H. Venter se appẽl by die NG Sinode van 1846 teen die lasterlike betiteling in die Herderlike Brief is verwerp. Ons moet raaksien hoe die kruks van die saak van 'n aanleiding oor Gesange oorgaan na 'n vraag van kerkregering. Watter gesag gebruik die kerkvergaderings en watter gesag wou die beswaardes gehoorsaam.

In Transvaal het die Regering met die kerk in 1858 ooreengekom dat die beswaardes van Rustenburg 'n eie gemeente binne die staatskerkopset sou kon vorm. Toe ds. Postma egter onverwags uit die Christelike Geref. Kerk opdaag, het die Hervormde ds. van der Hoff besef hy en Postma verskil ingrypend en hy moet Postma buite die staatskerk hou, anders sal dit nie meer 'n "Hervormde" kerk wees nie. Gevolglik het ds. van der Hoff die Algemene Kerkvergadering op 11 Januarie 1859 so gelei dat op die ooreenkoms met van die Rustenburgers gedurende 1858 teruggekom word. Die besluit dat die Hervormde kerkinrigting met sy Gesange onverswak gehandhaaf sal word, het willens en wetens die beswaardes die deur gewys. Van der Hoff se oninskiklikheid het die Uitvoerende Raad dan ook geskok. Vandaar hulle pogings reeds April 1859 om die breuk te heel.

Nie die Gesange in die NG en NH Kerke as sodanig het die breuk in 1859 veroorsaak nie, maar wel die onversetlike poging om die Gesange af te dwing. Ds. P. Huet van die NGK kon destyds tereg die corsaak van die breuk aandui: die gereformeerdes wou nie in 
sake van die godsdiens nie gedwing wees nie. So sê die kerkraad van Reddersburg ook in 'n brief 14 Januarie 1860 aan prof. H. de Cock: "Ons word maar verplig omdat die Sinode so besluit het ... Daar word minder of nooit gevra nie: Is dit volgens Gods Woord?"

\section{Die bedieningsuraag}

Calvyn se kerkopvatting in sy Institusie staan radikaal teenoor die van Rousseau en A. Kuyper wat die kerk as instituut as vertrekpunt neem. Calvyn sê die kerk verskyn waar mense die Woord en Sakramente bedien en ontvang soos die Skrif dit leer, en die kerklike dissipline slegs met die Woord van God uitgeoefen word. Calvyn trek te velde teen ampsdraers en kerklike handelinge wat oor ander se gewetes buite die Skrif om wil heers en voorskryf. Heerssug en dwang sonder Skrifgesag het juis die Roomse optrede teen die Hervormers gekenmerk.

Calvyn se kerkbegrip kom in art. 29 NGB duidelik na vore. Die kerk is nie ' $n$ struktuur nie, maar wesenlik 'n bediening van genademiddelle in 'n vergadering van gelowiges. Die merktekens van die kerk wat art. 29 NGB noem, behoort tot die eindomlike van die plaaslike kerk. Toe die Rasionalisme egter die genootskaplike kerkopvatting na vore bring, is die merktekens van plaaslike kerke verkeerdelik op kerke as sinodale strukture toegepas. So het die Sinode van 1869 op aandrang uit Nederland die NHK as 'n "valse kerk" bestempel.

Die gereformeerde belydenis stel in art. 28 NGB ook duidelik die plig en verantwoordelikheid van elke gelowige om die kenmerke van art. 29 NGB op plaaslike kerke aan te lê om uit te maak waar die ware kerk van Christus aanwesig is. In hierdie verantwoordelikheid het mense in 1859/60 hulle van gemeentes afgeskei om weer 'n Skrifgebonde bediening op plaaslike vlak daar te stel. Hulle twyfel vir geen oomblik nie dat hulle kerk van die Here is. Hulle identifiseer dan ook elke gestigte gemeente afsonderlik by die betrokke politieke owerheid "als eene Vrije Gereformeerde Kerk" wat op die grondslag van die leer, diens en tug van die Sinode van Dordrecht 1618/ 19 wil bestaan.

Gereformeerd wees is in 1859 bepaal en genormeer met die vraag Is dit volgens Gods Woord? en nie deur wat wil die meerderheid, of wat wil die pous of wat wil die sinode nie. Hoe maklik kan die gesagspool nie van Skrif na die amp, die kerk of selfs demokrasie skuif nie! Hoe gewigtig het die struktuur nie na 125 jaar geword nie sonder dat die gewig deur die Skriftuurlikheid opgemaak word!

\section{OM NA 125 JAAR ROND TE KYK}

\section{Om dankbaar te wees}

Dit is ' $n$ cliché om te sê daar is baie om voor dankbaar te wees. Moontlik moet ons die Here vir slegs een saak dank: dat die geloof ten spyte van die 125 jaar nie opgehou het nie! 
Vanselfsprekend het ons Belydenisskrifte uit die verlede nie verander mie. Hoe aktueel is hulle egter vir ons mense vandag? Hoeveel self-besig-wees met die Woord van God vind ons by die mense wat vandag die kerk is? Die antwoord op hierdie vrae - eerder as verwysings na "lidmate" of "kerk" statistiek, onderwys, PU vir CHO, geboue of astronomiese beleggings - sal bepaal tot watter mate die kerk van Christus nog aanwesig is en sigbaar word in die gereformeerde kerk binne algemene sinodale verband.

Vir gelowige mense moet nie die kerkvraag nie, maar die bedieningsvraag vooropstaan: die geloof word deur die Gees en Woord gevoed en daarvoor het die Here genadiglik bedieninge daargestel (Ef. 4:11v). Dit is jammer dat die instellings van die Here vandag verbleek voor die aandag en aksent op "die kerk" as instituut, as die Woord van God net die aandag kon kry wat mense aan "die kerk" gee, sou die wêreld in S.A. anders gelyk het.

Ons kan ten spyte van al die sonde en gebreke, dankbaar wees in so ver prediking, kategese en huisbesoek mense nog kerk van die Here laat wees wat die Woord en Gees gehoorsaam. Kerklike bedieninge moet nie kerkstrukture bou nie, maar die Woord bedien waarmee God, die Gees, lewe herskep.

\section{Om oor te bekommer}

Daar is baie om oor te bekommer. Oor die bedreiging deur magte van ongeloof, van swart en wit heidendom, praat ons nie eers nie.

Ons eie hart en lewe word steeds bedreig deur ongehoorsaam. heid aan God. Sonde is om die doel te mis wat God vir ons daarstel. Ons mis die doel wanneer in ons kerk-wees die KERK uitgangspunt en doelpunt van ons godsdiens word. Die kerk is mense. Mense kan en het God en sy Woord al dikwels in kerk en godsdiens verplaas, selfs sonder om dit te bedoel. Ons is so besig met wat sê die kerk in plaas van wat sê die Bybel; wat doen die kerk in plaas van wat doen die Here; wat doen en gee mense vir die kerk in plaas van wat doen en gee die kerk aan die Here!

Die feit dat ons so rustig kan praat van die Geref. Kerk in SA en ONS KERK verraai dat kerk met sekulêre wêreldse organisasies gelykgestel word, want mense praat daarvan soos van byvoorbeeld die Nasionale Party as ONS party. Die kerkbegrip het so gesekulariseer, geïdentifiseer met 'n organisasie en ons ril daar nie eers meer van nie! Inteendeel, soos van die kerk as struktuur gepraat word, gee die indruk dit behaag omdat dit "ons" syne is.

Die Westerse wêreld glo soos die Grieke in die natuur wat ewolueer. Volgens die ewolusie bring gedurige veranderinge altyd net die jongste die beste en hoogste trap van ontwikkeling na vore. Verwag ons geslag werklik die toekoms van die Here - van herskepping of van natuurlike ewolusie? Worstel ons met politieke, ekonomiese en sosiale vraagstukke in die lig van Gods Woord of doen ons dit in die natuurlig van die rede? Het ons sonder die Woord werklik 'n verweer teen die genitief-teologië waarvan die anti-Chris hom vandag bedien? 
Aan die ander kant dreig die ontsaglike gevaar om te dink dat jy arriveer wanneer alles bly soos dit is. Dan gaan "gereformeerd"-wees op in uiterlike vorme en formele "lidmaatskap". Die kerkvraag laat ons praat van "lidmate" eerder as "gelowiges". Gaan "gereformeerd" vandag nog soos by Paulus, Luther, Calvyn en in 1859 om die eise van Gods Woord vir vandag? Wie voer die gesag in ons kerk-wees en in ons kerkvergaderings? Die Woord of die meerderheid in kerkraad en sinode? Sal 'n Geref. Sinode hom nog soos in die vorige eeu van uitspraak weerhou omdat daar in die Skrif oor die betrokke saak geen voorskrif is nie? Wat regeer oor kerkwees: Skrifgesag of Kerkgesag?

'n Mens kan ook bekommerd vra: is ons kerke nie te onbetrokke by wat in die wêreld aangaan nie? As die owerheid iets verwyt kan word, is daar gewoonlik gou aksie, maar hoedanig worstel plaaslike kerke met die probleme in eie gemeenskap waarmee die mense wat die kerk is elke dag te doen het? Het ons nie so impotent geword om saam na die lig van die Woord te soek nie, dat ons bang geword het om lewende probleme en verskille rustig en ewewigtig onder oë te sien nie?

\section{OM NA 125 JAAR VORENTOE TE KYK}

\section{Identifiseer ' $n$ enkele kwaal}

K. Runia wys in 'n studiestuk vir die GES dat A. Kuyper se onderskeiding "kerk as instituut" en "kerk as organisme" gereformeerde kerke se betrokkenheid by die lewe verlam het. Kuyper beperk kerkwees by suiwer institusionele handelinge en verwag dat die gelowiges allerlei substituut vereniginkies moet stig om in die gewone lewe van die grond te kom. Daarmee verloor die kerklike instellings (bedieninge) grootliks hulle relevansie tot die lewe. Die aandag vir die kerk as instituut verstar noodwendig in institusionalisme.

Daarteenoor roep die Here met sy Woord en Gees tot werk. Totius skryf so kragtig: hy wat geroep is, slaap nie meer nie, hy is buite en hy werk. Ken ons nog roeping? Dit is nie die predikante of instituut wat moet werk nie. Die Here roep die kerk, die gelowiges, die mense, mans, vroue en kinders tot diens op elke terrein van die lewe. Die kerklike bediening moet juis die kwaliteit van elke gelowige mens-wees bevorder sodat die mense waar God hulle ookal geroep het, Sy werk doen.

\section{Geroep-wees om te werk na buite}

Ons moet ons bevry van die Kuyper-model waarin kerk-wees losstaan van die lewe. Om ons heen gryns die huweliksnood, gesinsnood, politieke harwar met sy Christus-onwaardige ondertone van haat en twis, krisis in mensverhoudinge, rassisme selfs onder dekmantel van godsdiens, die armoedevraagstuk, kapitalisme wat te ver kan handuitruk, ag en sommer doodgewone dingetjies soos motorfietse wat straffeloos jong lewens af maai, terwyl ons in die kategismus iets bely oor moedswillig in gevaar begewe, maar ons tog nie juis bekommer nie. 
Die feit dat werk na buite nie in eie omgewing en in breër verband gesoek en geïdentifiseer word nie, veroorsaak dat daar nie met die Bybel geworstel word nie. Dit word aan ander oorgelaat om sonder die Bybel antwoorde te probeer gee. Die gevolg is dat Christene in Bybel- en God-lose aktiwiteite politieke, ekonomiese en sosiale terrein ingetrek word en eenvoudig die spel volgens die sekulêre reëls moet speel. Mense kan mekaar nie verdra nie. Hulle kan verskille nie waardeer as geleenthede om mekaar te verryk nie. Die verskil van mening wek slegs bitter emosie. Gebeur dit onder heerskappy van die Woord en Gees ter wille van die Here? - ek glo nie.

Geroep-wees om te werk na binne

Die norm "is dit volgens Gods Woord" roep elke gereformeerde onophoudelik in elke situasie op om te antwoord. Dit is sy gereformeerde verantwoordelikheid. Hy moet in sy hart en lewe goed en kwaad met die Woord uitmekaar haal. Daardeur ontdek hy die sonde primêr by homself. Dit is hy wat klein voor God er. klein voor die mens moet word. Sonder om aan God te verantwoord, kan die gelowige niks doen nie.

Geroep-wees om te werk na Bo

Die toekoms is leeg en donker sonder 'n bewuste verhouding met God. Die verhouding is 'n verbond. God het Hom verbind en Hy gee genade, liefde, geloof, hoop en toekoms. Hy open in Christus die troon van genade sodat elkeen op die regte tyd gehelp kan word. Omdat $\mathrm{Hy}$ gee, vra Hy ook: dat ons an Hom verbonde bly; dat ons uit Hom deur Hom en tot Hom lewe.

Om die toekoms sinvol in te gaan is nie 'n vraag na die Geref. Kerk nie, maar 'n Skrif- en geloofsvraag: gaan ons leef volgens Gods Woord?

(Gelewer voor Gereformeerdes in Boland 11.2.84). 